\title{
TRENDS MANAGEMENT APPLIED TO BRANDING AND CULTURAL MANAGEMENT
}

\section{GESTÃO DE TENDÊNCIAS APLICADA AO BRANDING E À GESTÃO DA CULTURA}

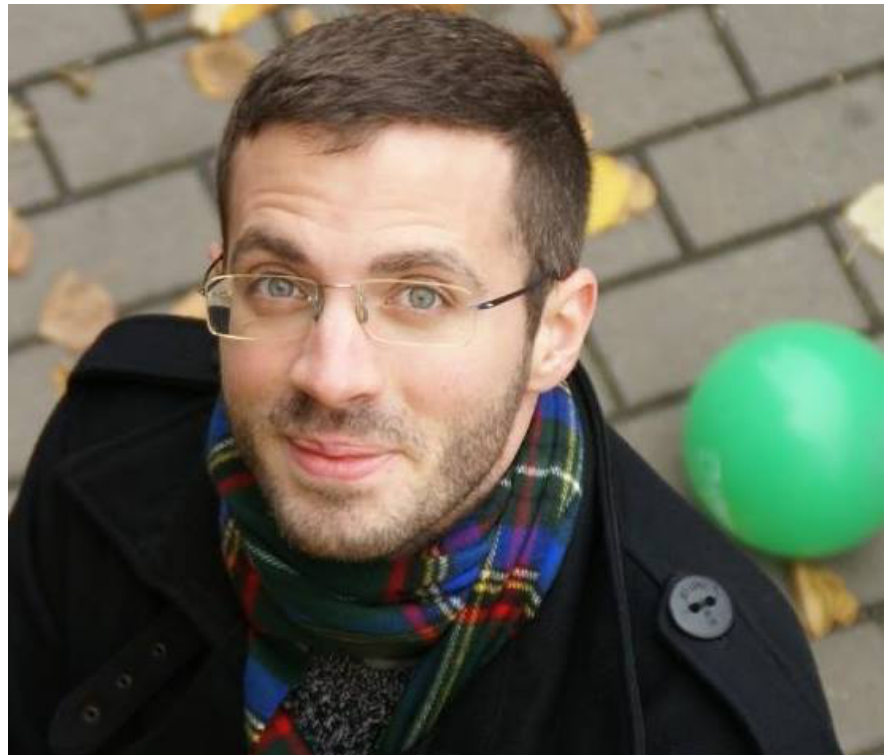

Nelson Pinheiro Gomes

Ph.D and Post-Doc. in Culture and Communication by the University of Lisbon

Invited Assistant Professor at the School of Arts and Humanities (University of Lisbon) and at the University Institute of Arts, Design and Enterprise (IADE-U) nelsonpinheiro@campus.ul.pt

\section{RESUMO}

Os estudos de tendências estão a dar os seus primeiros passos no meio científico, depois de já terem dado provas no campo empresarial e social. Importa agora, para além das questões teóricas e conceptuais, desenvolver os modelos científicos de aplicação do estudo das tendências, incluindo a sua principal ferramenta e disciplina: o coolhunting. A criação de modelos neste campo disciplinar permite criar padrões para a identificação e observação contínua de tendências, bem como para a sua aplicação na geração de inovação e de pistas para a tomada de decisões mais informadas sobre as grandes mentalidades e os padrões de comportamento dos consumidores. Este artigo pretende analisar as ferramentas e perspetivas existentes sobre o coolhunting e os estudos de tendências. Assim, propõe-se uma matriz integradora, com base na visão e nos desenvolvimentos portugueses da área, de vários modelos que em conjunto permitem estudar e aplicar as 
tendências ao nível da gestão de marcas, sem descurar a gestão da cultura.

\section{PALAVRAS-CHAVE}

Estudos de Tendências. Coolhunting. Branding. Gestão da Cultura.

\section{ABSTRACT}

Trends studies are giving their first steps in academia, after having proven themselves in the social and corporate fields. Now it is important to develop scientific models for the application of trends studies, including their major tool and discipline: coolhunting. The creation of models in this disciplinary field allows the creation of standards in the identification and continuous observation of trends, as well as their application in the generation of innovation and in decision-making insights, regarding major mindsets and consumer behavior patterns. The goal of this paper is to analyze the existing tools and perspectives on coolhunting and trends studies. Therefore, the creation of a complex matrix is proposed, based on the Portuguese perspective and developments in this field, with several combined models that promote the study and the application of trends on branding, without overlooking cultural management.

\section{KEYWORDS}

Trends Studies. Coolhunting. Branding. Cultural Management.

\section{INTRODUCTION}

Trends studies have been rapidly finding their way into academia as a new field that researches mindset and cultural trends, which manifest themselves in behavior patterns and cultural manifestations or artifacts. Trends studies articulate several perspectives and tools from sociology, ethnography, cultural studies, marketing, future studies and others, in order to provide a solid picture on social systems and innovation insights. With this potential, this field can work closely with branding and with cultural analysis. In fact, the goal of this paper is to underline how trends studies can develop formal tools and skills that are important for brand 
management, closely linked with cultural analysis. There are several gaps on the field and the goal of this paper is to help enlighten them. Firstly, it is important to review the most important authors and existing models and concepts applied on trends studies, mainly at a corporate level and not at an academic one. Secondly, it is necessary to underline the academic pertinence of trends studies and how they allow the training of different professionals, from the coolhunter to the trendwatcher. To this end, the main question of this paper is related to how trends studies can encompass and articulate a set of concepts, practices, tools and skills from different disciplines in a way that they can be used for strategic and creative management.

This paper is mainly developed under a specific literary review of the major trends studies authors (VEJLGAARD, 2008; GLOOR and COOPER, 2007; HIGHAM, 2009; RAYMOND, 2010), also considering the recent Portuguese research developments in this field. Based on the aforementioned literary review that presents the main views on the concepts and models of trends studies, we present a review of the Trends2 Innovation model (GOMES and FRANCISCO, 2013), in order to propose a more adaptable matrix of trends studies. Such matrix encompasses more models and visions, also being able to work in different combinations for several needs, problems and briefings. Thus, this new matrix will be an important tool in cultural analysis and brand management, being able to support the identification of new cultural discourses and behaviors; new lifestyle archetypes; new mindset trends; to transform cultural and trends insights into innovation; and to generate a large-scale zeitgeist picture.

With this new matrix, based on new and existing trends studies and innovation models, it will be possible to develop more complex researches and achieve better results for businesses and other institutions.

\section{TRENDS STUDIES: CONCEPTS, TOOLS AND MODELS}

When working with trends studies, there are several tools to consider and some of them are very specific to this field. One of those tools is coolhunting: the practice of identifying innovative cultural manifestations and seeds of change in mindsets and behaviors. However, there is no solid consensus on the role and nature of coolhunting. William Higham states that there is still no single established 
practice for the process of identifying and analyzing trends, underlining, there are few formal studies about the practice and the area (HIGHAM, 2009, p. 43). Nonetheless, the author adds that strong media coverage enabled the mainstream traction of coolhunting in the 1990s (HIGHAM, 2009, p. 45) and the practice gained a new international attention. Such promotion, however, did not help in the constitution of a united expertise, since each professional uses his own method and has a specific idea on its potential for application. Also, as Henrik Vejlgaard points out, the practice became a bit overrated since what was reported did not always developed into trends (2008, p. 188). Nevertheless, there is a general understanding that coolhunting allows to spot movements and changes and can lead to the identification of trends and innovation insights. That allows us - in an academic perspective - to apply and integrate the concept and the practice in a trends studies' model. Peter Gloor and Scott Cooper add that there are two particular areas for the application of coolhunting: namely the observation of external markets and the development of internal innovation (GLOOR and COOPER, 2007, p. 9).

When observing and studying the field, it is important for the coolhunter to consider the behaviors and symbols associated to trendsetters in their natural environment. Trendsetters are the first ones to adopt new behaviors and cultural artifacts, being in the center of symbolic renovation and, with a critical skill to observe and understand signs of change, the coolhunter must be close to them. As Martin Raymond suggested, when a coolhunter, while sharing different lifestyles and social tribes languages, observes three different manifestations with common characteristics - rule of the three times - (RAYMOND, 2010, p. 55), then he might be in the trail for a new behavior and it often emanates from the trendsetters.

Carl Rohde, cultural sociologist and CEO of Science of a Time, was a pioneer in this field, creating a methodology for the observation and registration of cool examples, which is still a base for the Portuguese practice of coolhunting. However, his annual reports (Trend Reports) and the website - www.scienceofthetime. com - themselves still do not suggest a clear associated scientific methodology and this is why it is still important to move efforts for the scientific consolidation of the practice. Faith Popcorn was another pioneer, positioning herself as a futurist, but again, she is more focused on the business aspect of trends research, being an important figure in the development and awareness of coolhunting.

Martin Raymond made an effort to create a model for trends' identification and analysis, one of the first ones, which influenced the Portuguese approach to trends studies. Firstly, it is important to underline that the author does not limit or close the definition of trend, which for him can be an idea or a set of similar forms and interconnected objects. A trend can also be an anomaly or the direction to which a difference is moving (RAYMOND, 2010, p. 13-14). His most interesting and 
transversal view on the nature of trends revolves around the idea that they can be cultural memes: an infectious idea that runs through the culture like a virus (RAYMOND, 2010, p. 15).

The author's idea of triangulation for trendspotting is to have three different but interconnected processes, from which the results confirm each other. This vision has three stages, namely (1) interrogation, (2) observation and (3) intuition (RAYMOND, 2010, p. 119-141). Martin Raymond explains the idea behind each stage:

Interrogation: the use of quantitative survey techniques, including household surveys and expert interviews, to poll individuals or groups about their attitudes or activities [...]. Observation: the use of a set of qualitative tools such as "ethnography" and "visual profiling" to shadow and observe individuals or consumers involved in a particular task or lifestyle activity [...]. Intuition: drawing in your experiences as a forecaster to add a further layer of insight to the qualitative and quantitative underpinnings acquired during the interrogation and observation stages. (Raymond, 2010, p. 120)

As the author suggest along his work, to identify the reasons behind the evolution of a trend requires looking at it as a cultural phenomenon and tracing the related societal factors that affect it. In this sense, it is possible to have an overall view on the different elements that impact and allow the identification of a trend. It is important to include coolhunting on this model and articulate it with the several stages, mainly with the stages of observation and intuition.

On a different perspective, Peter Gloor proposed the concept of coolfarming and made a distinction between the term and coolhunting, as one can notice hereafter (Table 1):

Table1 - Differences between Coolfarming and Coolhunting

\begin{tabular}{|l|l|}
\hline \multicolumn{1}{|c|}{ Coolfarming } & \multicolumn{1}{c|}{ Coolhunting } \\
\hline Gain power by giving it away & Search for COINs and self-organizing teams \\
\hline Seed community with idea & Search for ideas \\
\hline Mandate intrinsic motivation & Search for intrinsically motivated people \\
\hline Recruit trendsetters & Search for trendsetters \\
\hline
\end{tabular}

Source: GLOOR and COOPER, 2007, p. 92.

The author, along with Scott Cooper, explores the concept of coolfarming and underlines its four principles: (1) to gain power by giving it away / search for coins and self organization; (2) seed community with an idea / search for ideas; (3) 
mandate intrinsic motivation / search for intrinsically motivated people; (4) recruit trendsetters / search for trendsetters (GLOOR and COOPER, 2007, p. 92-99).

The (1) first principle implies an idea of empowerment and the feeling that everyone contributes with ideas and the (2) second one underlines the importance of coming up with new and innovative ideas outside of the box. The (3) third principle is about, as the authors state, "unleashing swarm creativity [...] to set an innovative idea free and share knowledge for free in a community" (GLOOR and COOPER, 2007, p. 95). If this idea grows and the community develops it, then we have the seeds for a new trend. This relates to the (4) fourth and last principle, since the growth requires leaders that set behaviors and taste.

This approach sees the development of trends seeds and new ideas in a community incubator environment. It is different from the most common perspective of trends studies, where trends emerge on society and the role of the trends experts is to identify, to interpret and to take insights from it. However, it is interesting to adapt and to develop this concept in a team of coolhunters and analysts, in order to create a community that can influence the perspective and analysis of trends with a specific vision.

Henrik Vejlgaard, one of the most important authors on trends studies, developed the diamond model, which categorizes the several archetypes of individuals in relation to how they adopt new behaviors and cultural manifestations (VEJLGAARD, 2008). In other words, this model is of the greatest importance

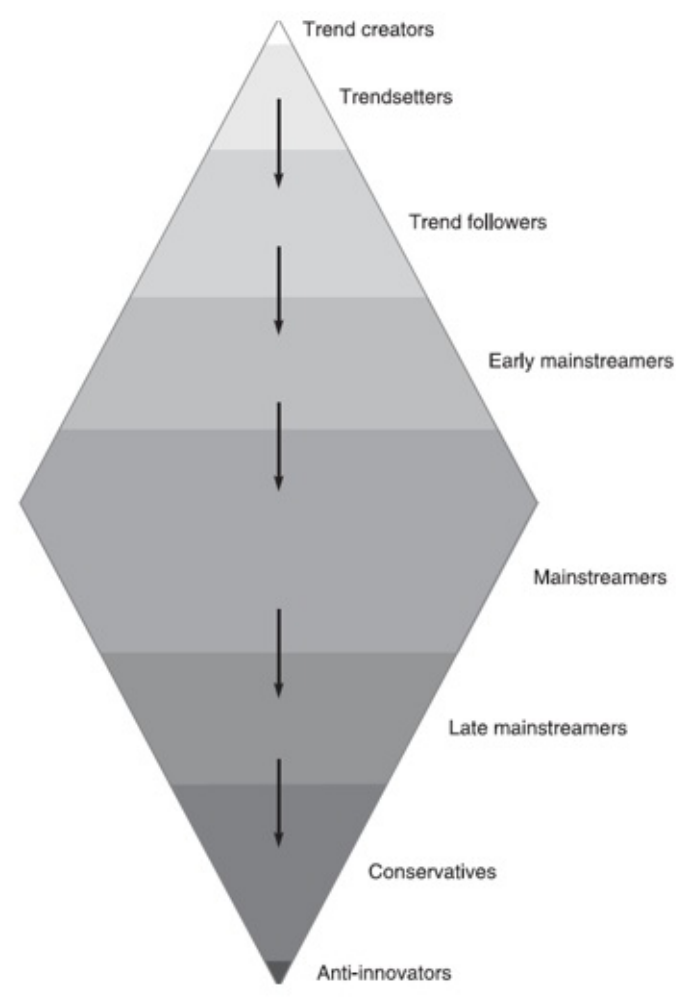

Source: VEJLGAARD, 2008, p. 64 
for coolhunting and trends analysis, since it shows how different public profiles appropriate a trend and how this trend develops in society:

The author created this model to study the fashion industry in the 1990s, but he adapted it to study trends and consumer behaviors. Henrik Vejlgaard explains the several groups present in the model:

\footnotetext{
The Trendsetters are the most open and curious individuals with regard to style and taste [...]. The trend followers are a bit like the trendsetters, but they need to have seen other people use the innovative new styles before themselves will use them. [...] Early mainstreamers accept new styles just before the majority [...] Mainstreamers are average in their acceptance of new, innovative styles [...] Conservatives prefer styles that have existed for years or even decades. They are the people who are the most skeptical of new styles. (Vejlgaard, 2008, p. 71-72)
}

These categories are crucial to understand the dissemination of new mindsets and behaviors. Although a trend emerges from the unconscious mind of a collective, only a few individuals have the capacity to interpret it and generate something innovative - the trend creators. Only some people can understand the growth potential of these new manifestations and seeds, adopting it in their lifestyles and disseminating it to other groups. All coolhunting and trends analysis practices must consider these different groups.

The Portuguese perspective on trends studies takes all these models, concepts and practices into consideration and develops the field based on these contributions. The Trends2innovation (T2I) (GOMES and FRANCISCO, 2013) created by the research group of Trends Observer was the first Portuguese and concrete international effort to articulate the several perspectives, models, concepts and practices of trends studies; incorporating skills, tools and knowledge from fields such as anthropology, cultural sociology, marketing, semiotics and design. This is an integrated trendspotting, trendwatching and innovation model, based on the study of mindset trends and derived behaviors. In fact, it became one of the cornerstones for the Portuguese perspective on trends studies. Today, it is still one of the most complete models for trends studies, drawing knowledge from several authors and experts, as we will soon demonstrate.

For the purpose of this work, it is important to review the mentioned T2I model and go through its elements in order to identify new possibilities for innovation. The first stage of the model addresses cultural analysis; considering the observation, interrogation and intuition perspective proposed by Martin Raymond (2010). The main objective of this stage is to gather the necessary data for analysis. From coolhunting to desk research, queries, interviews, anthropological analysis and zeitgeist topics definition, this is a continuous process for the coolhunter and 
the trends analyst. On the second stage, we gather the data into boxes according to similarities and potential. When certain data point to the same nature, then it is possible that we are observing the emergence of a new mindset. We may confirm this by studying the several pieces of data in the light of societal drivers, PEST analysis, zeitgeist topics comparison and by considering the specific places, prescribers and proposals associated with the manifestations. At the end of this stage, we have several groups of validated information. These groups are now associated with mindset and behavior patterns that are confirmed in the third stage, where the analyst gives a name to the patterns and proposes several scenarios and descriptions of each pattern and mindset (GOMES, 2015). Several experts and analysts must discuss these scenarios and descriptions in order to attribute to the final scenario the name and the description of the trend. These three stages represent the first part of the model dedicated to the spotting and monitoring of trends (GOMES and FRANCISCO, 2013).

The last two stages working as the second part of the model focus on the translation of trends into strategic insights. These stages are oriented for the application of trends analysis with the goal of developing strategic insights to business, politics and social development (GOMES and FRANCISCO, 2013).

Although this model integrates the two most important applications of trends studies - trendspotting and monitoring, as well as the generation of insights for innovation -, its form is not fluid enough to integrate new perspectives and to articulate new developments in the field. To this end, it is important to develop a new approach that can easily adapt to new discoveries and developments.

\section{THE TRENDS STUDIES MATRIX}

Recent Portuguese studies and practices developed under the Trends Observer platform and workgroup (www.trendsobserver.com) showed that it is important to have an updated and fluid scheme for trends studies. Moreover, it is necessary to create a structure more capable of integrating new tools, perspectives and existing models. As such, we propose the development of a matrix that can accommodate different models, each of them with specific goals. The researchers may articulate and combine all or some of them with the view to achieve different purposes. The next two topics explore the proposal for the creation of an integrated matrix of trends studies.

The several concepts, tools and models that integrate the matrix possess a multiple qualitative approach, producing a multidisciplinary perspective. There are several objectives and processes taking place in the matrix, from coolhunting to innovation management and insight generation. From coolhunting to formal cultural analysis, zeitgeist analysis, ethnographic research and innovation ma- 
nagement, there are many skills and tools that provide multiple perspectives on consumer behavior, lifestyle developments and general social mindsets and behaviors. According to each briefing and professional, the several models can work together to produce specific results. For this, it is important to understand not only a first draft of the matrix but also how it aids the generation of new connections and relations:

Table2 - Trends Studies initial Matrix

\begin{tabular}{|l|l|}
\hline 1. Trendspotting \& Trendwatching & 3. Innovation Pipeline \\
\hline 2. Zeitgeist Segmentation Model & 4. Lifestyle Archetypes \\
\hline
\end{tabular}

The initial models to compose a trends studies matrix and analysis must start with:

1) Trendspotting \& Trendwatching. This first model is the root of the matrix and the basis for trends studies. Its goal is to identify and to monitor trends using the most current tools of coolhunting and trends research. The goal of trendspotting is to identify new trends/patterns or new derivations from trends that have a distinct DNA and that are emerging as new mindset patterns, whilst trendwatching is about monitoring the trends, their developments and evolutions. Despite these differences, the processes imply the same approach:

a)Coolhunting is the first tool of the model, looking out for the weak signals of change, and emerging seeds of new behaviors and mindsets that show themselves on a creative and innovative form in society. They represent attitudes, the search for these trends' manifestations and objects implies the lookout for the cool, for meaning in all sociocultural manifestations that are creative, attractive, inspiring and have social replication potential. The registration of these seeds is the first step to identify new trends.

b)Quantitative and Qualitative Data. From clippings to desk research and reports analysis, this practice is about gathering data on what is changing in different sources and sectors in our society.

c)Applied Cultural Analysis. From cross-cultural analysis, to visual profiling and the analysis of the genius loci, it is important to base the research in its cultural context. The goal is to correctly context the research within a specific cultural frame, so that it is possible to take into account locals tribes, behaviors, dynamics, and tastes.

Once we gather the main data, we must divide it into "boxes", where we (the analysts) combine and articulate data and signals that appear to have relationships and connections. We must put these boxes under review. For that, we 
apply a PEST analysis in order to generate an integrated view on the topics at hand. When the PEST analysis confirms the information on the boxes to be relevant and coherent, the analysts propose texts and descriptions for the trend. These texts and descriptions also go through discussions within a trends analysts and coolhunters network, using a Delphi Model or other similar process to develop a more profound and solid view/description of the trend's nature. Once they reach a consensus, the team name the trend and publish its final description for public use.

This is a continuous process, in which the coolhunter and trends analyst are permanently searching for new seeds and reviewing the already existing trends, according to more recent collected data.

2) Zeitgeist Segmentation Model. This model (GOMES, 2015) dwells on the identification of the major spirit of the time topics, meaning the most important themes that are present in the consumer's collective mind, like "fear", "crisis", "migration", "interactivity", among many others. The identification of these topics is a continuous process developed with a large number of individuals, and it allows for the creation of a broad picture of the zeitgeist. When the topics are placed in an axis, they can be articulated with brand analysis and even urban tribes, according to how close each subject is to a cluster of topics (GOMES, 2015).

3) Innovation Pipeline. There are several interpretations and visions on the innovation pipeline. Trends Studies applied the model using trends insights as one of the basis to start the process (GOMES, 2015). The objective is to generate innovative solution to business and social problems, considering available resources and strategic ideation, according to the most pertinent trends and their insights, capable of providing a solid basis for the generation of innovation.

4) Lifestyle Archetypes. This model also proposes to analyze the emergent culture of cool, in order to identify major behavior patterns with social cohesion. Thus, here we are dealing with social tribes, groups and mainstream, or underground, associations. The objective is to identify consumer profiles and archetypes according to their lifestyle patterns.

This search can be developed according to a specific business or institutional briefing, or to identify the main archetypes by lifestyle patterns. From the universe of the research, several topics are analyzed and inquired upon, in order to identify and define specific lifestyle archetypes and their relations to the studied brands or respective categories. The definition of the groups/archetypes must encompass the analysis of:

a)Zeitgeist and Mindsets. This models can use and take advantage of the research results on the model 1 and 2 . The objective is to identify the most important trends and zeitgeist topics for each group. 
b)Biotypes. The objective is to study how biotypes metrics can influence lifestyle choices and can be articulated with lifestyle archetypes.

c)Symbolic Capital. It is important to understand how each group reads culture, especially visual culture, and what are the main references.

d)Lifestyle. The objective is to understand big patterns in taste, regarding food, music, television, cinema, sport, arts and culture, as well as fashion. It is important to underline that coolhunting can be a very important tool in this analysis and research.

With all this information, it is possible to identify the groups and archetypes by proximity of interests and behaviors, articulating this information with brand DNA and strategy.

\section{TRENDS MANAGEMENT: POTENTIAL FOR ACTIVATION IN BRANDING AND CULTURAL MANAGEMENT}

In an ever growing liquid world (see BAUMAN, XXX), it is important to have flexible but sound tools and models, in order to generate innovation and help brands to better manage culture and cultural shifts. This topic explores the professional potential of trends studies and the proposed matrix, ads in the identification of mindset trends and in the application of those insights to better business practices, according to the needs of each brand.

Today, there is still a big of a mix regarding the nomenclatures associated with trends studies professionals. The lack of a solid academic background is an open ground for the appearance and poor application of expressions like coolhunting and trendwatching. William Higham underlines that there are different concepts and perspectives on the identification and analysis of trends:

Perhaps because of its brief and multifaceted history, the process of trend analysis has yet to gain an agreed name. As trends became more important, different names were used to describe the process of analyzing them. One early term was "futurology". Later, several early adopter industries used the term "cool hunting". The most common terms today are based around the world "trend", such as "trend spotting", "trend forecasting" or "trend prediction". [...] Equally difficult to pin down is the word for a practitioner of trend studies. (Higham, 2009: 45)

The Portuguese perspective on trends studies uses mainly the expressions coolhunter and trends analyst. However, it is important to go over the many names in use and to articulate them in a comprehensive structure, taking advantage on the meaning of the names themselves. The following table tries to shed some light into this matter: 
Table3 - Trends Studies Professionals

\begin{tabular}{|c|c|c|}
\hline $\begin{array}{l}\text { Most common } \\
\text { international } \\
\text { nomenclatures }\end{array}$ & $\begin{array}{l}\text { Corresponding } \\
\text { nomenclature in } \\
\text { the Portuguese } \\
\text { perspective }\end{array}$ & Skills Explanation and Articulation \\
\hline Coolhunter & Coolhunter & $\begin{array}{l}\text { Qualitative and ethnographic research in several } \\
\text { media and on the field, in order to identify and spot } \\
\text { signals, seeds and creative manifestations of } \\
\text { alterations in behaviors, representations and } \\
\text { mindsets. }\end{array}$ \\
\hline Trendspotter & & $\begin{array}{l}\text { Responsible for the articulation of the registered } \\
\text { data and for the identification of new behavior } \\
\text { patterns that derive from changes in the mindsets }\end{array}$ \\
\hline Trendwatcher & $\begin{array}{l}\text { Trends Architect } \\
\text { and Analyst }\end{array}$ & $\begin{array}{l}\text { Trends monitoring, meaning their evolutions, } \\
\text { developments and mutations, identifying clues for } \\
\text { the generation of innovation in several fields. } \\
\text { Together, the trendspotter and the trendwatcher } \\
\text { have the necessary skills to develop the } \\
\text { architecture of trends, but only the trendwatcher, } \\
\text { as a trends analyst, can translate trends into } \\
\text { insights for innovation and better management } \\
\text { practices. }\end{array}$ \\
\hline- & Trends Archeologist & $\begin{array}{l}\text { Historic research on the evolution of the many } \\
\text { behavior and mindset patterns. This allows for the } \\
\text { identification of change catalysts and for a safer } \\
\text { prediction of changes in mindsets. }\end{array}$ \\
\hline
\end{tabular}

Source: Conception of the author.

All of these professionals can work with brand managers, each one with his/hers specific skills. Although the coolhunter can provide interesting cool benchmarks, the trends analyst can better articulate himself/herself with the brand manager, working on the translation of trends for strategic brand insights about the consumer and the cultural shifts. By translating trends into strategic insights for the generation of innovation, of a better dialogue with the consumer and of better management and communication practices for the brand, the trends analyst can have a very important role in brand management and even work as a Chief Culture Officer. When the trends analyst can articulate skills and knowledge of cultural analysis and the management of culture for enterprises, then he/she becomes a Chief Culture Officer, position originally conceived and proposed by Grant McCracken (2011).

It is important to underline that the relations between branding, culture and trends all fall within the scope of cultural analysis. When we speak of cultural management, we can underpin a new approach that studies cultural movements and objects, in order to generate a better understanding of the consumer, how to 
communicate and to create for him/her. From another perspective, trends studies also deal with cultural analysis, since they observe sociocultural behaviors based on their manifestations and artifacts. In other words, both trends studies and cultural analysis are exercises that provide a better insight on how the world is changing and how people are reacting to stimuli and new mindset trends. With this information, it is possible to create brand narratives and discourses appeal to the audience and mid-long term strategies for brand management. By articulating the several models of the trends studies matrix, one can obtain the necessary strategic insights and inspiration for creative and solid management of a brand.

\section{FINAL CONSIDERATIONS}

The study of cultural trends is a recent view on human behaviors that emerges and disseminates in groups and individuals, due to mutations on mindsets that must be identified through cultural manifestations, or artifacts, and associated behaviors. To understand cultural trends is to have an insight into lifestyle developments, power relations and what is emerging as innovative in society. This new view adds interpretative perspectives to cultural studies and broadens its impact potential, creating close articulations with consumer culture, marketing, branding, management, design and other areas that are of particular interest to the creative industries.

This paper presented some of the most influential views on trends studies and coolhunting from authors like Henrik Vejlgaard and Martin Raymond, in order to underline the state of the art regarding the most important concepts and tools for trends analysis and consumer culture interpretation. In articulation with the Portuguese developments on trends studies, we have a solid perspective on the potential of trends studies to generate innovation. The goal of this work was to put all this knowledge into context, in order to produce an updated matrix to apply to trends studies' models and concepts.

The here proposed Trends Studies Matrix is flexible and allows to develop better and more focused studies, resulting into a larger number of potential outputs, but with more information to confirm the insights. This matrix contributes to the state of the art by giving an integrated perspective on trends studies and by underlining the full potential and broad scope of the trends studies' field.

This essay consists of a theoretical review and model conceptualization 
work. Therefore, in future opportunities we wish to test the new matrix on case studies that can confirm and improve the proposal. The test of each model in the matrix and their main articulations will provide valuable insights on trends identification and management. Considering the growing interest for trends studies and the many academics and professionals that want to specialize in this field, this paper should serve as a basis to explore and to acquire a clear view on the potential of applications in the field of trend research.

\section{REFERENCES}

GLOOR, Peter; COOPER, Scott. Coolhunting: Chasing down the next big thing. New York: Amacom, 2009.

GOMES, Nelson P.“Comportamento de Consumo, Elites Sociais e Moda. Contributo para a consolidação disciplinar dos estudos de tendências". PhD Thesis in Culture and Communication, University of Lisbon, Lisbon 2015.

GOMES, Nelson P.; FRANCISCO, Ana. Introdução aos Estudos de Tendências: Conceitos e Modelos. Lisbon: Trends Research Center, 2013.

HIGHAM, William. The Next Big Thing. London: Kogan Page, 2009.

MCCRACKEN, Grant. Chief Culture Officer. How to create a living, breathing corporation. New York: Basic Book, 2011 [2009].

RAYMOND, Martin. The Trend Forecaster's Handbook. London: Laurence King, 2010.

VEJLGAARD, Henrik. Anatomy of a Trend. New York: McGraw-Hill, 2008.

Nelson Pinheiro Gomes is a member of the teaching staff of the Culture and Communication Program - School of Arts and Humanities (University of Lisbon), acting as the co-coordinator of the Post-Graduate Diploma Course in Trends Communication. He is also responsible for the scientific coordination of the Trends Observer - Consumer Culture \& innovation research sub-group of the Creative Cultures: Cities, Trends Management Consortium (promoted by organic units of the University of Lisbon). With a research focus on cultural trends studies, as well as cultural branding and management, he completed his

Recebido em: 14/03/2016; Aceito em: 20/04/2016.

Esta obra foi licenciada com uma Licença Creative Commons. $\mathrm{PhD}$ and Post-Doctorate in Culture and Communication (ULisbon), as well as an MA in Cultural Sciences, an MBA and several post-graduate certificates and diplomas on Fashion, Urban Policies and Economics, Coolhunting, European Policies, among others. He is also a researcher at ULICES (University of Lisbon Centre for English Studies). 